Revue d'histoire de l'Amérique française

REVUE D.HISTOIRE DE L'AMÉRIQUE FRANÇAISE

THOMPSON, John Herd et Stephen J. RANDALL, Canada and the United States. Ambivalent Allies (Montréal, McGill-Queen's University Press, 1994). 22,95 \$

\title{
Stephen Kenny
}

Volume 49, numéro 2, automne 1995

URI : https://id.erudit.org/iderudit/305436ar

DOI : https://doi.org/10.7202/305436ar

Aller au sommaire du numéro

Éditeur(s)

Institut d'histoire de l'Amérique française

\section{ISSN}

0035-2357 (imprimé)

1492-1383 (numérique)

Découvrir la revue

Citer ce compte rendu

Kenny, S. (1995). Compte rendu de [THOMPSON, John Herd et Stephen J. RANDALL, Canada and the United States. Ambivalent Allies (Montréal, McGill-Queen's University Press, 1994). 22,95 \$]. Revue d'histoire de l'Amérique française, 49(2), 291-293. https://doi.org/10.7202/305436ar d'utilisation que vous pouvez consulter en ligne.

https://apropos.erudit.org/fr/usagers/politique-dutilisation/ 
THOMPSON, John Herd et Stephen J. RANDALL, Canada and the United States. Ambivalent Allies (Montréal, McGill-Queen's University Press, 1994). 22,95\$

Cette étude, divisée en deux parties de valeur très inégale, se veut un survol des rapports canado-américains depuis les années 1770 jusqu'à l'ALENA. La première moitié du livre, d'une longueur d'environ 300 pages, 
traite de toute l'histoire de ces rapports, jusqu'en 1941, tandis que la seconde moitié est consacrée aux dernières cinquante années.

Dès les premières pages du premier chapitre de l'ouvrage, l'interprétation des professeurs Thompson et Randall transparaît on ne peut plus clairement. Le point de vue de ces deux anciens collègues du Département d'histoire de l'Université McGill, dont l'un se trouve maintenant en Caroline du Nord et l'autre en Alberta, est éminemment américain. En voici deux exemples.

Dans le premier chapitre, les auteurs caractérisent l'invasion prérévolutionnaire du Canada de 1775 comme un épisode de «defensive expansionism», une expression qui révèle bien leur parti pris. En effet, si on se place dans l'optique du Canada, on est plutôt en droit de se demander si le remède de l'un n'est pas le poison de l'autre. Après tout, une invasion défensive de la part d'un envahisseur n'est-elle pas, au fond, qu'une attaque agressive pour celui qui est envahi?

De la même façon, lorsqu'ils traitent de la guerre de 1812, les auteurs acceptent ce qu'ils appellent le consensus traditionnel. En d'autres termes, le conflit fut provoqué par les grands principes liés aux questions maritimes et surtout par le désir d'affirmation de la jeune république devant la puissante ingérence de la Grande-Bretagne. Le Canada ne fut qu'un otage, l'annexion de ses terres, peu prioritaires, ou dans les mots des auteurs, «a distant secondary consideration», tandis que la question de la légitimité des prétentions aborigènes n'est même pas abordée.

En ce qui concerne le désir des États-Unis d'acquérir du territoire comme mobile de cette guerre, Thompson et Randall nous assurent que la plupart des historiens l'excluent. De surcroît, ils prétendent que seulement certains enseignants canadiens du secondaire insistent sur cette question. Estil possible que cette insistance à voir les choses autrement soit due au simple fait que, à l'encontre de la situation qui prévaut dans les départements d'histoire des universités (du moins au Canada anglais), le personnel de nos écoles secondaires soit d'origine canadienne? Quoi qu'il en soit, on peut aussi ajouter que le consensus dont les auteurs tirent leurs conclusions sur la guerre de 1812 est presque entièrement basé sur des sources américaines.

Ne serait-ce que pour l'équilibre de l'analyse, n'aurait-il pas été souhaitable de prendre en considération la perspective canadienne sur de tels sujets? Appelons un chat un chat. Comme ces deux exemples le démontrent, la première moitié du livre laisse à désirer. En plus des problèmes d'interprétation déjà notés, on remarque aussi quelques erreurs de faits; ainsi, on y affirme que George Brown fut le ministre des finances dans le gouvernement d'Alexander Mackenzie et que la Première Guerre mondiale s'est terminée en novembre 1919.

Les auteurs semblent beaucoup plus à l'aise dans le traitement de l'époque contemporaine. En effet, la deuxième partie du livre, qui lui est consacrée, est beaucoup plus solide. D'ailleurs le sous-titre, Ambivalent Allies, tire son origine d'une réflexion sur les années du gouvernement Trudeau. Dans cette partie, les auteurs délaissent les sources secondaires, 
souvent vétustes, sur lesquelles leur étude était basée jusque-là, pour entamer une analyse beaucoup plus approfondie et intéressante. On y retrouve un examen impressionnant de fonds d'archives présidentiels, de mémoires des premiers ministres, de débats parlementaires, de documents officiels, ainsi qu'une analyse d'un large éventail de sources secondaires. Compte tenu de cette richesse documentaire et du traitement efficace qu'en font les auteurs, la lecture de cette dernière partie est plus satisfaisante.

Thompson et Randall y affirment, entre autres, que l'esprit des relations canado-américaines actuelles s'est défini en 1948 principalement parce qu'au début de la guerre froide, le Canada a perdu son contrepoids britannique. Laissé seul face à la nouvelle superpuissance américaine qui allait mener la lutte de la liberté dans un nouveau monde dangereusement polarisé, le Canada devait tenter de se tailler une place au plan international tout en protégeant ses propres intérêts. Malgré ses efforts, son champ d'action s'est dramatiquement rétréci. Sans doute, la leçon la plus troublante pour le Canada au cours de cette période a-t-elle été une perte d'indépendance dans la conduite de ses affaires extérieures. Face au géant américain, il n'avait plus qu'à suivre.

Dans leur discussion très détaillée des différentes approches empruntées par les chefs de gouvernement canadien en matière de relations avec les États-Unis, les auteurs mettent en relief la situation difficile du Canada. Dans la phrase qui suit, les qualificatifs utilisés sont les miens, pas les leurs. Peu importe l'attitude du premier ministre canadien, que ce soit «l'antagonisme» de Diefenbaker, «la collusion» de Pearson, «l'indifférence» de Trudeau, «la servilité» de Mulroney (ajouterais-je «la réticence» de Chrétien?), le Canada compte peu aux yeux des États-Unis. Depuis cette ère moderne, aucun leader canadien n'a réussi à changer ni même à modifier les projets du gouvernement américain. 